\title{
Effect of integrin-linked kinase gene silencing on microRNA expression in ovarian cancer
}

\author{
DANDAN YUAN $^{1 *}$, YILEI ZHAO ${ }^{2 *}$, YANG WANG ${ }^{2}$, JIANHUA CHE $^{1}$, WENHUA TAN $^{1}$, YUXIA JIN $^{1}$, \\ FEI WANG ${ }^{1}$, PEILIANG LI ${ }^{1}$, SHUYAN FU ${ }^{1}$, QIAN LIU ${ }^{1}$ and WENLIANG ZHU ${ }^{3}$ \\ ${ }^{1}$ Department of Obstetrics and Gynecology, Second Affiliated Hospital of Harbin Medical University; ${ }^{2}$ Department \\ of Pharmacy, First Affiliated Hospital of Harbin Medical University; ${ }^{3}$ Institute of Clinical Pharmacology, \\ Second Affiliated Hospital of Harbin Medical University, Harbin, Heilongjiang 150086, P.R. China
}

Received August 16, 2016; Accepted July 11, 2017

DOI: $10.3892 / \mathrm{mmr} .2017 .7523$

\begin{abstract}
Integrin-linked kinase (ILK) is overexpressed in ovarian cancer (OC), and $I L K$ gene silencing results in apoptosis in OC cells. In the present study, the mechanism by which ILK induces apoptosis was explored from the perspective of microRNA (miRNA) expression. Alterations in the global miRNA expression profile were detected using a miRNA microarray after OC cells were transduced with an ILK small hairpin RNA lentivirus. ILK silencing led to a significant upregulation of 14 miRNAs by at least 1.5 -fold. These findings were validated by reverse transcription-quantitative polymerase chain reaction. A pathway analysis of experimentally validated target genes revealed the inhibition of multiple cancer-associated signaling pathways and the wnt signaling pathway. Compared with cells transfected with scrambled RNA, the ILK-silenced cells had remarkably lower expression of wnt ligands (wnt3a, wnt4 and wnt5a) and downstream $\beta$-catenin. ILK silencing led to apoptosis of OC cells and impaired the migratory ability. Taken together, the present
\end{abstract}

Correspondence to: Dr Qian Liu, Department of Obstetrics and Gynecology, Second Affiliated Hospital of Harbin Medical University, 246 Xuefu Road, Harbin, Heilongjiang 150086, P.R. China

E-mail: luoluo_liu@sina.com

Dr Wenliang Zhu, Institute of Clinical Pharmacology, Second Affiliated Hospital of Harbin Medical University, 246 Xuefu Road, Harbin, Heilongjiang 150086, P.R. China

E-mail:wenzwl@yeah.net

*Contributed equally

Abbreviations: ILK, integrin-linked kinase; FDR, false discovery rate; KEGG, Kyoto Encyclopedia of Genes and Genomes; miRNA, microRNA; MTI, miRNA-target interaction; OC, ovarian cancer

Key words: ovarian cancer, integrin-linked kinase, microRNA, wnt pathway results suggested that miRNA-mediated wnt pathway alterations are involved in the anti-apoptotic role of ILK in OC. It was also indicated that $I L K$ silencing reduced the ability of OC cells to adhere to fibronectin, which may lead to unstable focal contact. Consistently, the phosphorylation levels of focal adhesion kinase and RAC- $\alpha$ serine/threonine protein kinase were downregulated. The present work demonstrated the first global miRNA expression profile of OC cells when ILK was inhibited, and this expression profile may provide a basis for the development of biomarkers and therapeutic targets for OC.

\section{Introduction}

Ovarian cancer (OC) is a common female gynecological cancer. Although the incidence of $\mathrm{OC}$ is lower than those of cervical and endometrial cancer, the case-fatality ratio of $\mathrm{OC}$ is the highest among all gynecological tumor types $(1,2)$. Owing to the lack of effective methods for early diagnosis and the nonspecific symptoms, $\mathrm{OC}$ is typically detected at the advanced stage (3). Furthermore, the incidence of $\mathrm{OC}$ is projected to increase (4) and the 12-year case-fatality rate has only slightly declined in the past few decades (5). Accordingly, novel methods clarifying the mechanisms of OC development are urgently needed in order to improve the early detection and to identify novel therapeutic targets improving the patient survival rate.

Integrin-linked kinase (ILK) has multiple roles in the pathological procession of OC $(6,7)$. As an important integrin-proximal kinase, the over-activation of ILK is implicated in cancer cell growth and tumor angiogenesis $(8,9)$. In contrast, $I L K$ gene silencing induces OC cell apoptosis in vitro (10) and suppresses tumorigenesis of OC cells in vivo (11). These observations indicate that ILK may be a useful biomarker and a therapeutic target for OC treatment. Functional interactions between ILK and other biological factors have also been identified to enhance its anti-apoptotic role in tumor cells. For example, synergistic interactions between ILK and the wnt signaling pathway contribute to the acceleration of breast tumor progression (12). Additionally, ILK upregulation is significantly correlated with the downregulation of miR-542-3p in human colon cancer tissues (13). The activated wnt signaling pathway promotes epithelial-mesenchymal 
transition via microRNAs (miRNAs/miRs) (14), whereas its inhibition results in apoptosis of OC cells (15-18).

In the present study, interactions among ILK, the wnt signaling pathway and miRNAs were investigated in OC cells. The hypothesis that ILK inhibition leads to the inactivation of the wnt signaling pathway via the upregulation of miRNAs was examined. A microarray analysis was performed to reveal global alterations in the miRNA expression profile in OC cells when the $I L K$ gene was silenced. The present results provide novel insight into the mechanisms underlying the functional interactions between ILK and other biological factors in OC.

\section{Materials and methods}

ILK short hairpin (sh)RNA expression lentivirus. An ILK shRNA expression lentivirus that was described and applied previously was used in the present study (10). The primer sequences of the shRNA targeting human ILK and the scrambled shRNA (negative control, NC) were as follows: 5'-TCAACCAGGGGACGATCAT-3' and 5'-TTCTCCGAA CGTGTCACGT-3', respectively (Shanghai GenePharma Co., Ltd., Shanghai, China).

Cell culture and transfection. The A2780 human OC cell line was purchased from Shanghai BoQuaner Biological Science and Technology Ltd., Co. (Shanghai, China), and the cells were cultured in $10 \%$ fetal bovine serum (FBS)-RPMI-1640 (Thermo Fisher Scientific Inc., Waltham, MA, USA) in a 5\% $\mathrm{CO}_{2}$ humidified $(95 \%)$ incubator at $37^{\circ} \mathrm{C}$. Cells were seeded into 6 -well plates $\left(5 \times 10^{5}\right.$ cells/well) and allowed to adhere for $24 \mathrm{~h}$ at $37^{\circ} \mathrm{C}$. Subsequently, the cells were transduced with the ILK lentivirus or NC lentivirus $\left(1 \times 10^{8} \mathrm{TU} / \mathrm{ml}\right)$ and continuously cultured for another $12 \mathrm{~h}$ at $37^{\circ} \mathrm{C}$. Fresh medium was then replaced with RPMI-1640 supplemented with $10 \%$ FBS and lysed for $72 \mathrm{~h}$. The number of green fluorescent protein-positive cells was determined by an inverted microscope (Axio VertA1; Carl Zeiss, Oberkochen, Germany).

Cell viability assay. Cells were cultured in 96-well microtitration plates at a density of $5 \times 10^{4}$ cells/well. Cell viability was assessed by measuring mitochondrial dehydrogenase activity. After lentiviral transfection, $10 \mu 1$ 3-[4,5-dimeth-ylthiazol-2-yl]-2,5-diphenyl-tetrazolium bromide (MTT; $5 \mathrm{mg} / \mathrm{ml}$; Sigma-Aldrich; Merck KGaA, Darmstadt, Germany) was added to each well for $4 \mathrm{~h}$ at $37^{\circ} \mathrm{C}$ in the dark. Subsequently, the purple formazan crystals were dissolved in $200 \mu$ l dimethyl sulfoxide. Absorbance was read at $540 \mathrm{~nm}$ using a spectrophotometer.

Western blot assay. Cells in 6-well culture clusters were growth-arrested with RPMI-1640 supplemented with $10 \%$ FBS for $24 \mathrm{~h}$ at $37^{\circ} \mathrm{C}$, prior to ILK lentivirus (cat no. 34314-1) or NC lentivirus (cat no. LVCONO77) (both from Shanghai Genechem Co., Ltd., Shanghai, China) infection. After the lentiviral transfection for $72 \mathrm{~h}$ at $37^{\circ} \mathrm{C}$, cells were lysed with lysis buffer and incubated for $30 \mathrm{~min}$ on ice. The lysates were subsequently sonicated and centrifuged for $10 \mathrm{~min}$ at $4^{\circ} \mathrm{C}$ $(14,800 \mathrm{x} \mathrm{g})$, and the insoluble fraction was discarded. Protein samples $(50 \mu \mathrm{g})$ were subjected to $10 \%$ SDS-PAGE and blotted on a nitrocellulose membrane. The blots were blocked with
$5 \%$ nonfat milk for $2 \mathrm{~h}$ at room temperature and probed with primary antibodies, including ILK (cat no. ab52480; 1:1,000 dilution), $\beta$-catenin (cat no. ab32572; 1:1,000), phosphorylated (p)-focal adhesion kinase (FAK; Tyr397; cat no. ab81298; $1: 1,000), \mathrm{p}-\mathrm{RAC}-\alpha$ serine/threonine protein kinase (Akt; Ser473; cat no. ab81283; 1:1,000) and $\beta$-actin (cat no. ab8226; 1:1,000) (all from Abcam, Cambridge, MA, USA), in phosphate-buffered saline (PBS) and incubated at $4^{\circ} \mathrm{C}$ overnight. The membranes were washed with PBS with Tween-20 $(0.05 \%)$ and were incubated with a fluorochrome-conjugated secondary antibody (1:5,000 dilution; cat no. 150077; Thermo Fisher Scientific, Inc.) for $1 \mathrm{~h}$ at room temperature. Finally, bands were analyzed using the Imaging System and quantified using the Odyssey software (version 1.2) (both from LI-COR Biosciences, Lincoln, NE, USA) based on intensity (area $\mathrm{x}$ optical density) in each group with $\beta$-actin as an internal control. Results are expressed as the fold change by normalizing the data to the control values.

Measurement of caspase-3 activity. The Caspase-3 Activity kit was obtained from Beyotime Institute of Biotechnology (Haimen, China). Caspase-3 activity was measured based on the cleavage of a chromogenic caspase substrate, Ac-DEVD-pNA (acetyl-Asp-Glu-Val-Asp p-nitroanilide). The protein samples were prepared as indicated in the previous section (western blotting assay). Total protein $(50 \mu \mathrm{g})$ was added to the reaction buffer containing Ac-DEVD-pNA $(2 \mathrm{mM})$ and incubated for $4 \mathrm{~h}$ at $37^{\circ} \mathrm{C}$. The absorbance of yellow $p \mathrm{NA}$ cleaved from its corresponding precursors was subsequently determined using an ultraviolet spectrometer at $405 \mathrm{~nm}$. The specific caspase-3 activity, normalized with the total proteins from cell lysates, was expressed as the fold change of the baseline caspase activity which was measured from normal cells cultured in Dulbecco's modified Eagle's medium (Thermo Fisher Scientific, Inc.) supplemented with $10 \%$ FBS.

Cell migration and invasion assays. To analyze wound healing, SKOV3 cells were seeded in 6-well plates at a density of $5 \times 10^{5}$ cells/well with RPMI. When the cells reached $80 \%$ confluency, they were infected with the ILK or NC lentivirus. After $48 \mathrm{~h}$, the cell monolayer was wounded using a plastic pipette tip. Cells were subsequently rinsed with PBS and cultured with serum-free RPMI for $24 \mathrm{~h}$ at $37^{\circ} \mathrm{C}$. The wound closure was observed and imaged under a phase-contrast microscope (Olympus Corporation, Tokyo, Japan). For the Transwell assays, $8-\mu \mathrm{m}$ pore size chambers (Corning, Inc., Corning, NY, USA) were used with or without an insert coated with Matrigel (BD Biosciences, San Jose, CA, USA). A total of $48 \mathrm{~h}$ after infection with the ILK or NC lentivirus at $37^{\circ} \mathrm{C}, 1 \times 10^{5}$ cells in serum-free medium were added to the upper chamber. The lower chamber was filled with $10 \%$ FBS RPMI. After $24 \mathrm{~h}$ of incubation at $37^{\circ} \mathrm{C}$, the cells remaining on the upper surface of the membrane were removed, whereas the cells that had invaded through the membrane were fixed with $100 \%$ methanol for $15 \mathrm{~min}$ at room temperature and stained with $0.1 \%$ crystal violet for $20 \mathrm{~min}$ at room temperature. Images of SKOV3 cells were obtained under a phase-contrast microscope (Olympus Corporation).

Cell adhesion assay. Cultures of SKOV3 cell lines were transduced with the ILK or NC lentivirus and harvested. 
Table I. Primer sequences for the genes used in the present study.

\begin{tabular}{lll}
\hline Gene name & \multicolumn{1}{c}{ Forward primer (5'-3') } & Reverse primer (5'-3') \\
\hline miR-15a-5p & GCGGCGGTAGCAGCACATAATG & ATCCAGTGCAGGGTCCGAGG \\
miR-29c-3p & GCGGCGGTAGCACCATTTGAAATC & ATCCAGTGCAGGGTCCGAGG \\
miR-30a-5p & GCGGCGGTGTAAACATCCTCGAC & ATCCAGTGCAGGGTCCGAGG \\
miR-200a-3p & GCGGCGGTAACACTGTCTGGTAAC & ATCCAGTGCAGGGTCCTCGAC \\
CTNNB1 & ACTAAACAGGAAGGGATGGAAGG & AGATGACGAAGAGCACAGATGG \\
ILK & GTCTCCACCTGCTCCTCATC & TCCTCATCAATCATTACACTACGG \\
wnt3a & TGGCCCCACTCGGATACTT & TGGGCATGATCTCCACGTAGT \\
wnt4 & CCTTCGTGTACGCCATCTCTTC & GCGATGTTGTCAGAGCATCCT \\
wnt5a & ATCGACTATGGCTACCGCTTTG & CCACATCAGCCAGGTTGTACA \\
U6 & GCTTCGGCACATATACTAAAAT & CGCTTCACGAATTTGCGTGTCAT \\
GAPDH & CATGTTCGTCATGGGTGTGAA & GGCATGGACTGTGGTCATGAG
\end{tabular}

The mature sequences of miR-15a-5p, miR-29c-3p, miR-30a-5p and miR-200a-3p are UAGCAGCACAUAAUGGUUUGUG, UAGCACCAU UUGAAAUCGGUUA, UGUAAACAUCCUCGACUGGAAG, and UAACACUGUCUGGUAACGAUGU, respectively. miR, microRNA; CTNNB1, catenin- $\beta 1$; ILK, integrin-linked kinase; U6, small nuclear ribonucleoprotein.

Following a 48-h incubation, cells ( $1 \times 10^{5} /$ well) were added to 96 -well plates coated with fibronectin $(5 \mu \mathrm{g} / \mathrm{ml}$; BD Biosciences), followed by a $2-\mathrm{h}$ incubation at $37^{\circ} \mathrm{C}$. Cells were washed by PBS three times. Subsequently, cells were incubated for $1.5 \mathrm{~h}$ in $10 \%$ Cell Counting Kit-8 (Dojindo Molecular Technologies, Inc., Kumamoto, Japan) in normal culture medium at $37^{\circ} \mathrm{C}$ for color conversion. Relative cell adhesion to fibronectin was calculated as the fold change in cell adhesion of normal cells to fibronectin, which was measured as the absorbance by using an ultraviolet spectrometer at $450 \mathrm{~nm}$.

Immunofluorescence analysis. Cells plated in 12-well chamber slides coated with fibronectin $(5 \mu \mathrm{g} / \mathrm{ml}$; BD Biosciences) were transduced with the ILK or NC lentivirus for $48 \mathrm{~h}$ at $37^{\circ} \mathrm{C}$. Following this, cells were fixed in $100 \%$ methanol, and blocking solution (1\% bovine serum albumin and $0.1 \%$ Triton X-100 in PBS) was added. Cells were incubated at room temperature for $2 \mathrm{~h}$ and were exposed to the primary antibody $\left(4^{\circ} \mathrm{C}\right.$, overnight). The following specific antibodies were used: ILK-1 (dilution, 1:500; cat no. ab76468) and Talin (dilution, 1:100; cat no. ab157808) (both from Abcam). Following this, cells were incubated with two fluorochrome-conjugated secondary antibodies (goat anti-rabbit IgG, Alexa Fluor 594, cat no. A11037; and goat anti-mouse IgG, Alexa Fluor Plus 488, cat no. A32723) (both from Thermo Fisher Scientific, Inc.) for $1 \mathrm{~h}$ at room temperature. The nuclei were stained using DAPI (Beyotime Institute of Biotechnology, Shanghai, China) for $20 \mathrm{~min}$ at room temperature. Immunofluorescence was examined under a fluorescence microscope (Nikon 80i; Nikon Corporation, Tokyo, Japan).

Total RNA extraction and microarray analysis. The lysed cells were centrifuged for $10 \mathrm{~min}$ at $4^{\circ} \mathrm{C}(450 \mathrm{x} \mathrm{g})$. TRIzol reagent (Thermo Fisher Scientific Inc.) was used to extract RNA from cells transduced with ILK or NC lentivirus. Three independent samples were examined for each group. The RNA eluate was stored at $-80^{\circ} \mathrm{C}$ for the microarray analysis. In the present study, the lentivirus-infected cell samples underwent global scanning of miRNA expression using the Agilent Human miRNA Microarray (Release 19.0, 8x60K). Briefly, sample labeling, microarray hybridization and washing were performed following the manufacturer's protocol (Agilent Technologies Inc., Santa Clara, CA, USA), as described previously (18). Differentially expressed miRNAs were identified based on the following criteria: fold change $>1.5$ and $P<0.05$. Only the probes flagged as 'Detected' in all samples were included in the analysis. 'Detected' indicates a positive normalized expression value detected for a probe. The miRNA microarray analysis was performed by Shanghai Oe Biotech Co., Ltd. (Shanghai, China). The microarray data were submitted to the Gene Expression Omnibus (accession no. GSE83721).

Reverse transcription-quantitative polymerase chain reaction $(R T-q P C R)$. To evaluate differentially expressed miRNAs, RNAs from normal A2780 cells and cells transduced with ILK or NC lentivirus were extracted using TRIzol reagent and the concentration was determined by ultraviolet spectrophotometry. After the RNA concentration and purity were quantified, RNA was used as a template for cDNA synthesis by RT. A quantitative analysis of genes was performed using the ABI 7500 Fast Real-Time PCR system (Applied Biosystems; Thermo Fisher Scientific, Inc.). The PCR conditions used to detect the genes were as follows: $95^{\circ} \mathrm{C}$ for $10 \mathrm{~min}$, followed by 35 cycles of $95^{\circ} \mathrm{C}$ for $15 \mathrm{sec}$ and $60^{\circ} \mathrm{C}$ for $1 \mathrm{~min}$. Intracellular mRNA levels of $I L K$, wnt $3 a$, wnt 4 , $w n t 5 a$ and catenin $\beta 1(C T N N \beta 1)$ were also detected in the three groups (the normal, NC lentivirus infection and the ILK lentivirus infection groups). GAPDH was used as an internal reference. Intracellular expression alterations in various miRNAs, including miR-15a-5p, miR-29c-3p, miR-30a-5p and miR-200a-3p, were also investigated in the three groups. Quantitation threshold $(\mathrm{Cq})$ values for each gene were normalized to those of $G A P D H$, and $\mathrm{Cq}$ values for miRNAs were normalized to U6. Relative expression levels were calculated using the following equation: $2^{-\Delta \Delta \mathrm{Cq}}(19)$. Table I presents the primer sequences for the genes. 
A
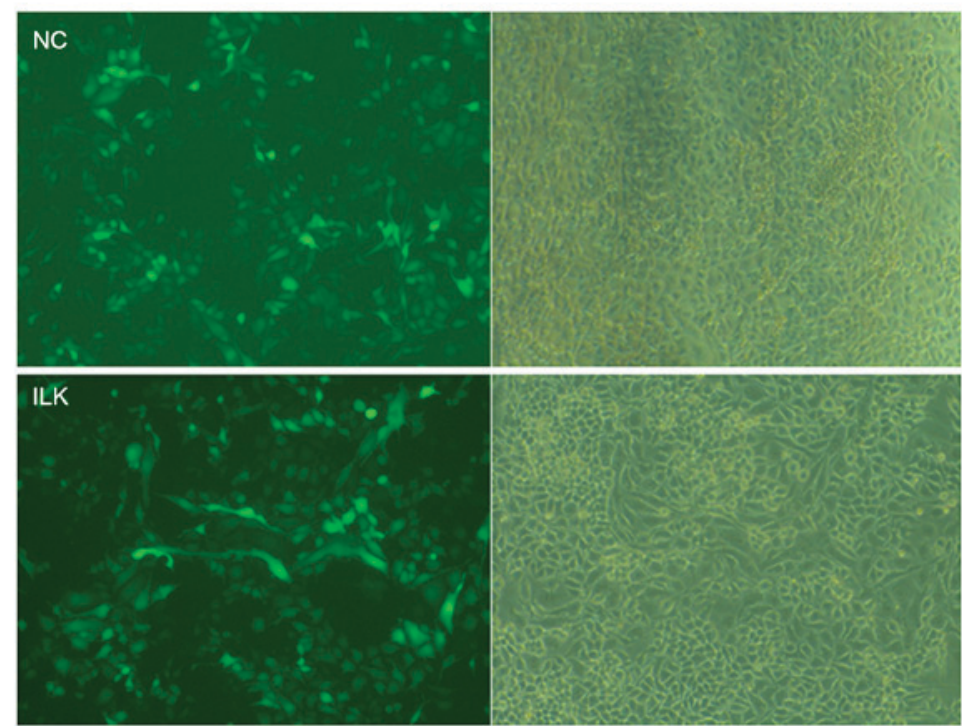

B

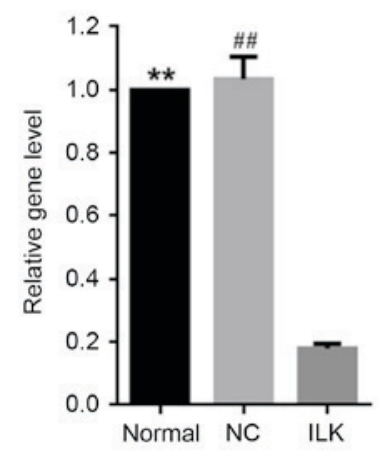

C
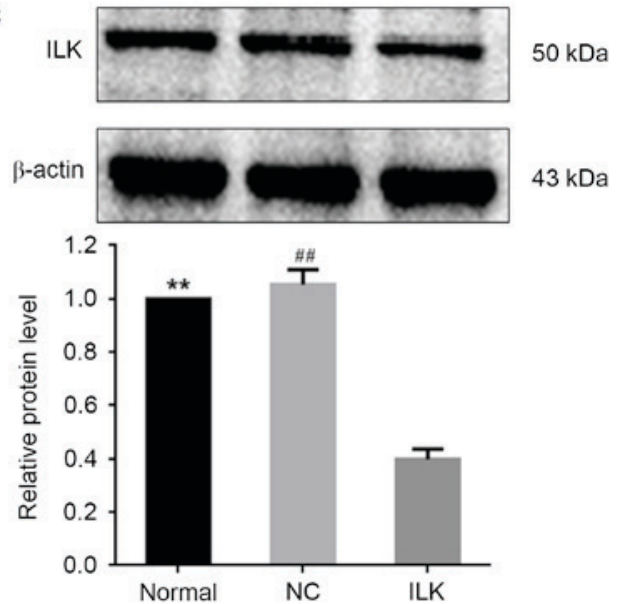

Figure 1. Influence of ILK shRNA lentiviral transduction on the gene and protein expression of ILK in OC cells. (A) Representative fluorescence images indicating transduced cells. Magnification, $x 100$. The (B) gene and (C) protein expression levels of ILK were silenced by lentiviral transduction ( $\mathrm{n}=3$ ). Data are expressed as the mean \pm standard error. ${ }^{* *} \mathrm{P}<0.001$ vs. normal cells; ${ }^{\# \#} \mathrm{P}<0.001$ vs. NC. ILK, integrin-linked kinase; sn, small hairpin; OC, ovarian cancer; $\mathrm{NC}$, negative control.

Pathway analysis. To explore the pathways affected by significantly dysregulated miRNAs in response to ILK silencing, a Kyoto Encyclopedia of Genes and Genomes (KEGG) pathway analysis was performed using the Database Annotation, Visualization and Integrated Discovery (DAVID) bioinformatics online tool (20). The miRTarBase database was used to obtain the set of experimentally supported miRNA-target interactions (MTIs) for the significantly dysregulated miRNAs in the microarray analysis and verified by RT-qPCR (21). Only the MTIs supported by at least one piece of strong evidence or by at least $\geq 2$ pieces of less strong evidence were retained for further KEGG pathway analyses. Strong evidence is the evidence that was validated by the reporter assay, western blot or qPCR; whereas, less strong evidence is the evidence that was validated by microarray, pulsed stable-isotope labeling by amino acids in cultured cells or next-generation sequencing. The official gene symbols of all targets of the miRNAs were uploaded to the database for the KEGG pathway analysis. Significantly over-represented pathways were identified when genes involved in a given pathway accounted for $>5 \%$ of the whole set of uploaded genes and the false discovery rate (FDR) was $<0.05$.

Statistical analysis. Data are expressed as the mean \pm standard error. Statistical analyses were performed with Student's t-test or one-way analysis of variance followed by Dunnett's test, where appropriate, using GraphPad Prism v6.0 (GraphPad software, Inc., La Jolla, CA, USA). P<0.05 was considered to indicate a statistically significant difference.

\section{Results}

Silencing of ILK by lentiviral transfection induces apoptosis in $O C$ cells. The shRNA lentiviral transfection was used for silencing the $I L K$ gene in OC cells. Lentiviral transfection markedly downregulated the intracellular expression of $I L K$ (Fig. 1A) and ILK mRNA expression (Fig. 1B). The protein expression of ILK was $\sim 60 \%$ lower in cells infected with the lentivirus vector expressing ILK shRNA than in normal cells (Fig. 1C). These results demonstrated 

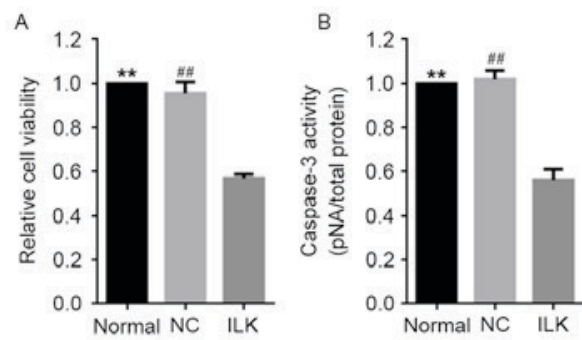

C
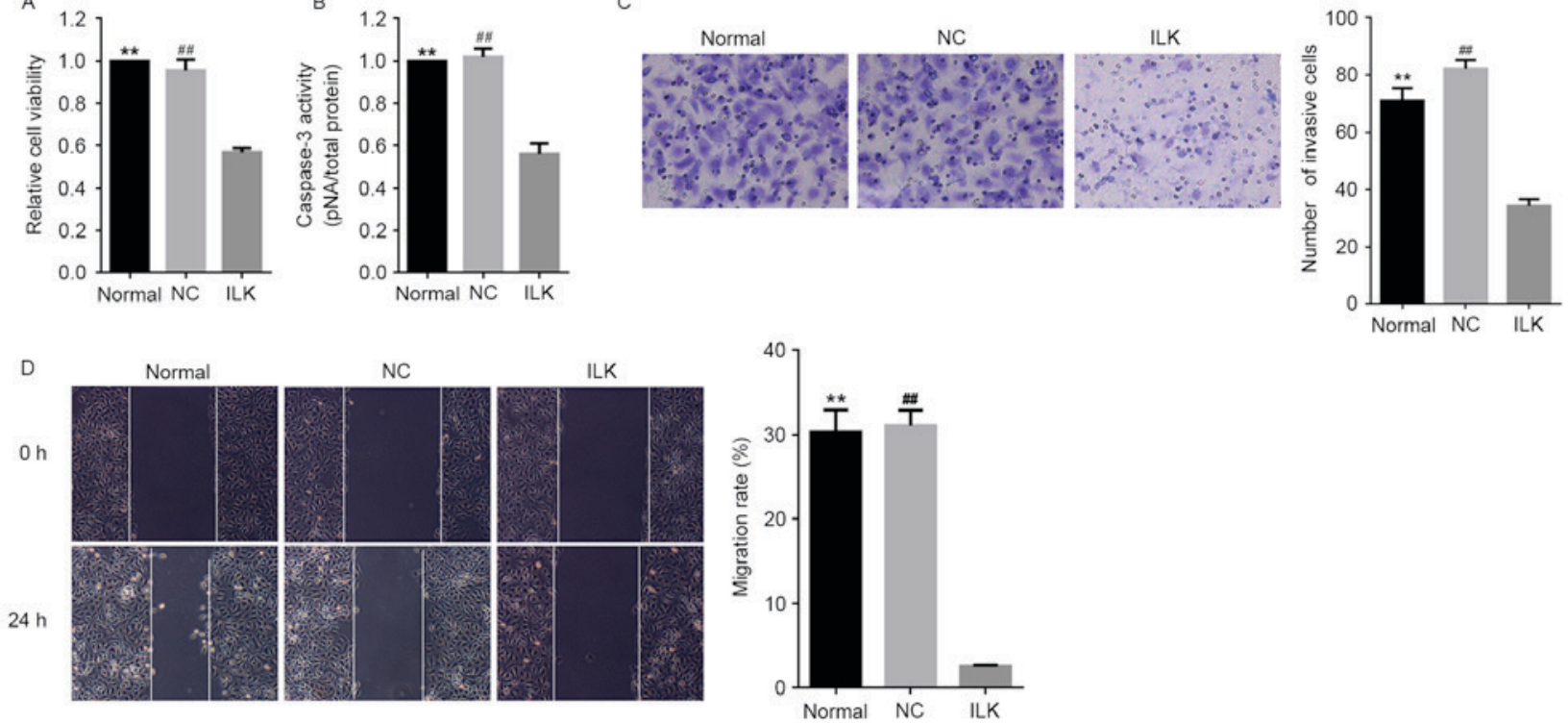

Figure 2. Influence of $I L K$ short hairpin RNA lentivirus transfection on (A) cell viability (n=6), (B) apoptosis (n=5), and migration of OC cells depicted by (C) Transwell and (D) cell scratch assays $(\mathrm{n}=3)$. Migration rate was calculated as the difference between the area between white lines at $0 \mathrm{~h}$ and that at $24 \mathrm{~h}$ divided by that at $0 \mathrm{~h}(\mathrm{x} 100 \%)$. Data are expressed as the mean \pm standard error. ${ }^{* *} \mathrm{P}<0.001$ vs. normal cells; ${ }^{* \#} \mathrm{P}<0.001$ vs. NC. ILK, integrin-linked kinase; NC, negative control.

Table II. Significantly upregulated miRNAs by ILK silencing.

\begin{tabular}{lcc}
\hline miRNAs & Fold change & P-value \\
\hline miR-29b-3p & 2.87 & $2.67 \times 10^{-2}$ \\
miR-551b-3p & 2.80 & $8.01 \times 10^{-3}$ \\
miR-30e-5p & 2.20 & $1.25 \times 10^{-2}$ \\
miR-135b-5p & 2.09 & $1.21 \times 10^{-2}$ \\
miR-301a-3p & 1.90 & $9.08 \times 10^{-3}$ \\
miR-96-5p & 1.84 & $1.48 \times 10^{-2}$ \\
miR-27a-3p & 1.83 & $4.67 \times 10^{-3}$ \\
miR-30a-5p & 1.77 & $7.78 \times 10^{-4}$ \\
miR-200a-3p & 1.76 & $1.68 \times 10^{-2}$ \\
miR-29c-3p & 1.68 & $5.48 \times 10^{-3}$ \\
miR-15a-5p & 1.63 & $9.97 \times 10^{-3}$ \\
miR-210-3p & 1.56 & $3.36 \times 10^{-2}$ \\
miR-106b-5p & 1.56 & $7.61 \times 10^{-3}$ \\
miR-181a-5p & 1.54 & $9.50 \times 10^{-3}$ \\
\hline
\end{tabular}

miRNAs, microRNAs; ILK, integrin-linked kinase.

the efficiency of ILK shRNA transfection via the lentivirus vector. A strong reduction in ILK expression significantly decreased cell viability and induced apoptosis in OC cells compared with normal conditions $(\mathrm{P}<0.01$, Fig. $2 \mathrm{~A}$ and $\mathrm{B}$ respectively). This finding strongly suggested that $I L K$ is a potent anti-apoptotic gene in OC cells and promotes the pathological development of OC, consistent with our previous study (10). ILK silencing led to a remarkable reduction in the migratory ability of OC cells (Fig. 2C and D). Consistently, $I L K$ silencing led to the reduced migratory ability of $\mathrm{OC}$ cells (Fig. 2C and D). No significant influence of lentiviral transfection alone was detected on ILK expression and the overall state of OC cells.

Multiple miRNAs are significantly upregulated when ILK is silenced. To explore whether miRNAs mediate the anti-apoptotic functions of ILK, global miRNA expression in OC cells was examined after ILK shRNA lentivirus transfection. The microarray assay revealed 294 miRNAs that were expressed in the cells (accession number: GSE83721). Among them, 14 were significantly upregulated by $I L K$ silencing ( $>1.5$-fold change and $\mathrm{P}<0.05$, Table II). However, no miRNA was significantly downregulated by $I L K$ silencing. Four miRNAs (miR-15a-5p, miR-29c-3p, miR-30a-5p and miR-200a-3p) were selected for further validation using a RT-qPCR assay ( $\mathrm{P}<0.01$, Fig. 3 ). The miRNA miR-200a-3p exhibited the greatest fold change ( $\sim 17.2$ fold) compared with the control cells. As $I L K$ is a vital anti-apoptotic gene in OC (10), the strong change in miR-200a-3p expression suggests that it has a vital role in OC.

miRNAs mediate functional interactions between ILK and multiple cancer-associated signaling pathways. Using the miRTarBase database, 366 experimentally validated MTIs were identified for 13 of the 14 dysregulated miRNAs (Table II) and 331 mRNA genes. The analysis did not identify any gene as a target of miR-551b-3p. By searching the 331 genes against the DAVID website, nine significantly over-represented KEGG pathways were obtained, including focal adhesion, cell cycle, wnt signaling and six cancer-associated pathways (Table III). These results supported the anti-apoptotic role of ILK in OC cells. It is possible that the remarkable upregulation of the miRNAs suppresses cancer-associated signaling pathways and leads to apoptosis.

ILK silencing down-regulates phosphorylation of FAK and Akt and reduces cell adhesion. The pathway analysis 
Table III. Significantly overrepresented KEGG pathways (FDR <0.05).

\begin{tabular}{lccc}
\hline KEGG pathway & Gene (no) & \% (331 genes in total) & FDR \\
\hline Pathways in cancer & 44 & 13.7 & $7.60 \times 10^{-18}$ \\
Focal adhesion & 25 & 7.8 & $1.00 \times 10^{-7}$ \\
Prostate cancer & 22 & 6.8 & $1.80 \times 10^{-12}$ \\
Chronic myeloid leukemia & 20 & 6.2 & $1.10 \times 10^{-11}$ \\
Small cell lung cancer & 20 & 6.2 & $1.00 \times 10^{-10}$ \\
Cell cycle & 20 & 6.2 & $1.80 \times 10^{-7}$ \\
Pancreatic cancer & 19 & 5.9 & $7.40 \times 10^{-11}$ \\
Colorectal cancer & 17 & 5.3 & $1.70 \times 10^{-7}$ \\
Wnt signaling pathway & 17 & 5.3 & $1.00 \times 10^{-3}$
\end{tabular}

KEGG, Kyoto Encyclopedia of Genes and Genomes; FDR, false discovery rate.

A

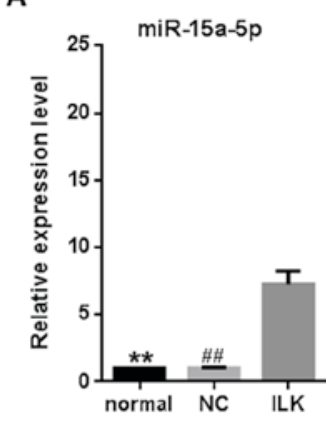

C

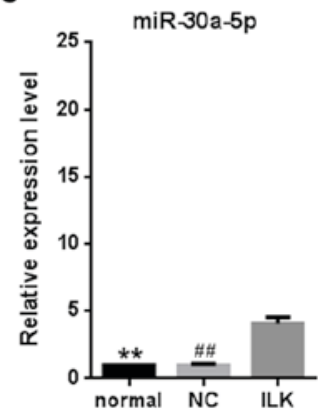

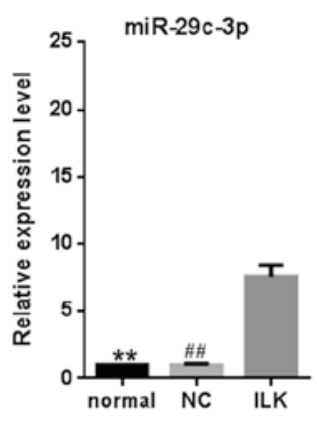

D

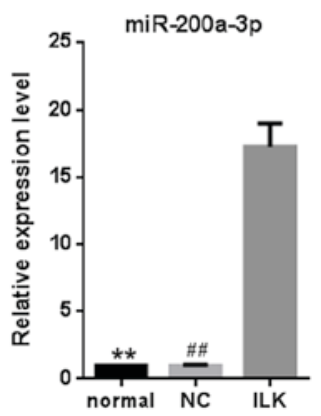

Figure 3. Reverse transcription-quantitative polymerase chain reaction validation of (A) miR-15a-5p, (B) miR-29c-3p, (C) miR-30a-5p and (D) miR-200a-3p $(n=3)$. Data are expressed as the mean \pm standard error. ${ }^{* *} \mathrm{P}<0.001$ vs. normal cells; ${ }^{\# \#} \mathrm{P}<0.001$ vs. NC. miR, microRNA; ILK, integrin-linked kinase; $\mathrm{NC}$, negative control.

revealed an overrepresentation of target genes of dysregulated miRNAs involved in focal adhesion $\left(\mathrm{FDR}=1 \times 10^{-7}\right)$. Consistent with these findings, ILK silencing markedly reduced the ability of OC cells to adhere to fibronectin (Fig. 4A). The FAK/Akt signaling pathway serves an important role in pressure-stimulated cancer cell adhesion (22). ILK silencing led to decreases in the phosphorylation levels of FAK and Akt by $\sim 70 \%$ and $\sim 50 \%$, respectively (Fig. $4 \mathrm{~B}$ and C). This result suggests that the FAK/Akt signaling pathway was markedly inactivated by $I L K$ silencing in OC cells. It was observed that ILK silencing led to the concomitant downregulation of talin, another important constituent element of the focal adhesion complex that stabilizes the cytoskeleton, and kinases, such as

ILK-1 (Fig. 4D). This result implies that ILK silencing might result in the formation of unstable focal contact.

ILK silencing reduced the activity of the wnt signaling pathway via multiple miRNAs. Multiple studies have demonstrated that overactivation of the wnt signaling pathway is involved in the pathological development of OC $(17,23,24)$. Four of the 14 dysregulated miRNAs that are illustrated in Table II regulate genes involved in the wnt signaling pathway, i.e. miR-15a-5p, miR-29c-3p, miR-30a-5p and miR-200a-3p and are involved in the post-transcriptional regulation of wnt $3 a$, wnt4, wnt5a, and CTNNB1, respectively (25-28). CTNNB1 encodes $\beta$-catenin, a crucial signaling factor in the wnt signaling pathway. In the present study, these four miRNAs were upregulated when ILK was specifically silenced in OC cells (Fig. 3). Consistent with this, reduced expression of their target genes in the wnt signaling pathway was observed, suggesting weakened wnt activity (Fig. 5A-D). The protein expression of $\beta$-catenin decreased by $\sim 45 \%$ when $I L K$ was silenced (Fig. 5E).

\section{Discussion}

After activation by hormones, growth factors and cytokines, the multidomain focal adhesion protein serine/threonine kinase ILK is overexpressed, and this overexpression is causally associated with changes in cell survival, migration, and angiogenesis $(8,9)$. Accordingly, ILK has a well-known role in the progression of hormonal cancers, such as OC (29). It has previously been suggested that silencing of $I L K$ leads to apoptosis in OC cells (10), but the mechanisms mediating this effect are unclear. Accordingly, extensive investigations of the roles of ILK in OC are necessary $(1,2)$. Many recent studies have suggested that miRNAs are involved in the progression of OC and serve important roles in various cellular functions, including cell survival and migration (30-35). In the present study, the influence of ILK on global miRNA expression was explored by applying microarray techniques. Lentivirus-mediated silencing of ILK caused the marked upregulation of 14 miRNAs in OC cells. A functional pathway analysis revealed the crucial involvement of ILK in multiple cancer-associated signaling pathways. 


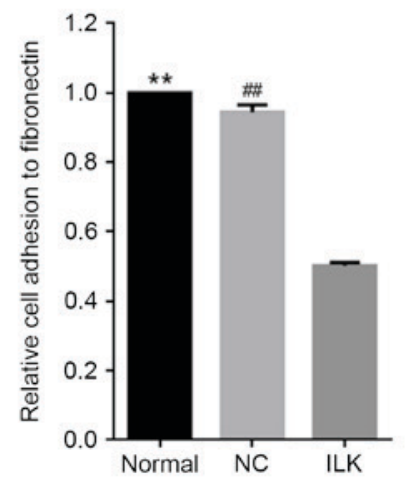

B
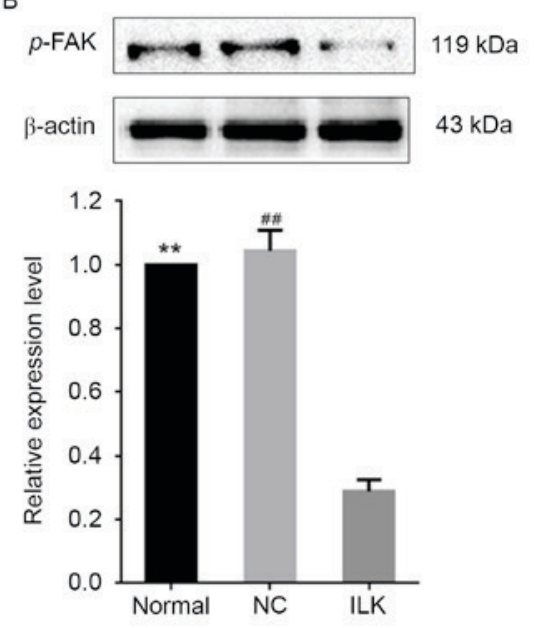

D

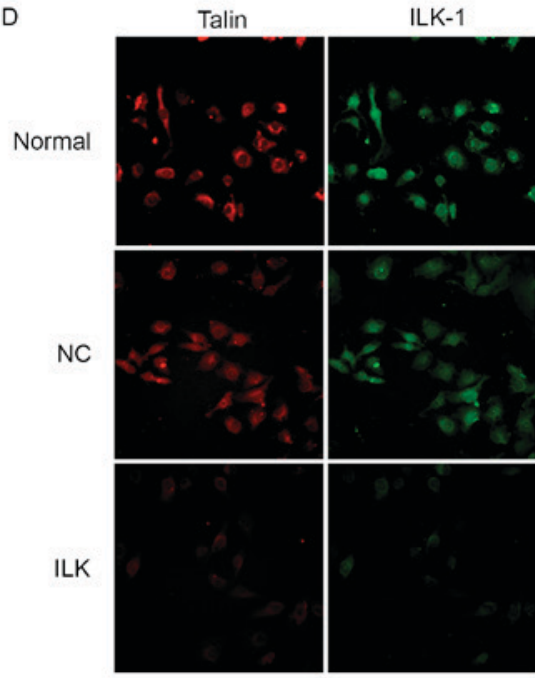

$\mathrm{C}$
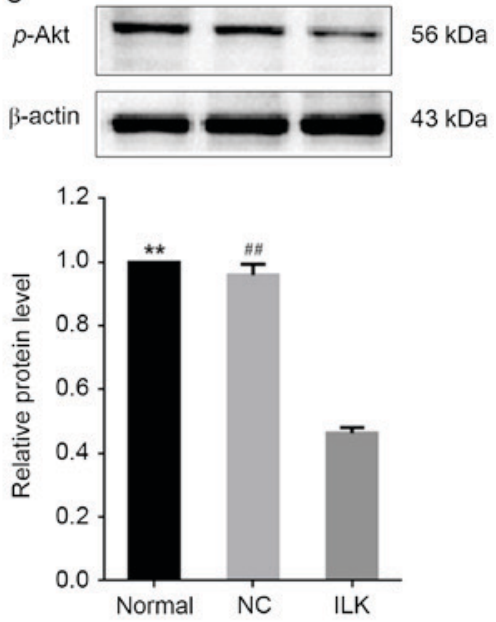

Talin/ILK-1/DAPI
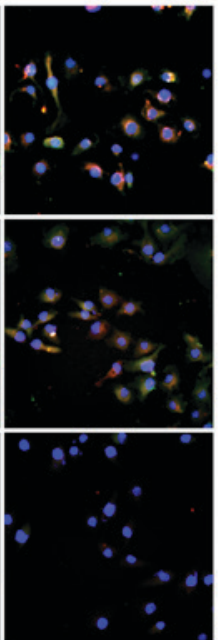

Figure 4. ILK silencing reduces (A) the adhesion of OC cells to fibronectin $(\mathrm{n}=3)$ and the activity of the FAK/Akt signaling pathway by downregulating the phosphorylation of (B) FAK and (C) Akt in OC cells $(n=3)$. This was also demonstrated by (D) fluorescence microscopy where co-localization of ILK (green) and talin (red) was investigated (Magnification, $\mathrm{x} 100$ ). Data are expressed as the mean \pm standard error. ${ }^{* *} \mathrm{P}<0.001$ vs. normal cells; ${ }^{\# \#} \mathrm{P}<0.001 \mathrm{vs}$. NC. FAK, focal adhesion kinase; Akt, RAC- $\alpha$ serine/threonine-protein kinase; ILK, integrin-linked kinase; NC, negative control.

In the progression of OC, the overexpression of ILK in cancer cells could activate multiple downstream singling pathways, such as the vascular endothelial growth factor and Akt signaling pathways, and eventually stimulate cancer cell phenotypes, such as survival, migration and angiogenesis (29). Consistent with the results of a previous study (10), the present study validated that the transfection of OC cells with the ILK shRNA lentivirus resulted in decreased ILK expression, at both the mRNA and protein expression levels.
When ILK was silenced, reduced cell viability and lower capase-3 and cell migration ability were observed, indicating the tumor-promoting effect of ILK in OC cells. These results suggested that the specific inhibition of ILK is a feasible strategy for OC treatment $(11,36)$.

It was also observed that $I L K$ silencing caused global alterations in miRNA expression. A signature composed of 14 upregulated miRNAs was associated with $I L K$ silencing in OC cells. The KEGG pathway analysis of their targets revealed 

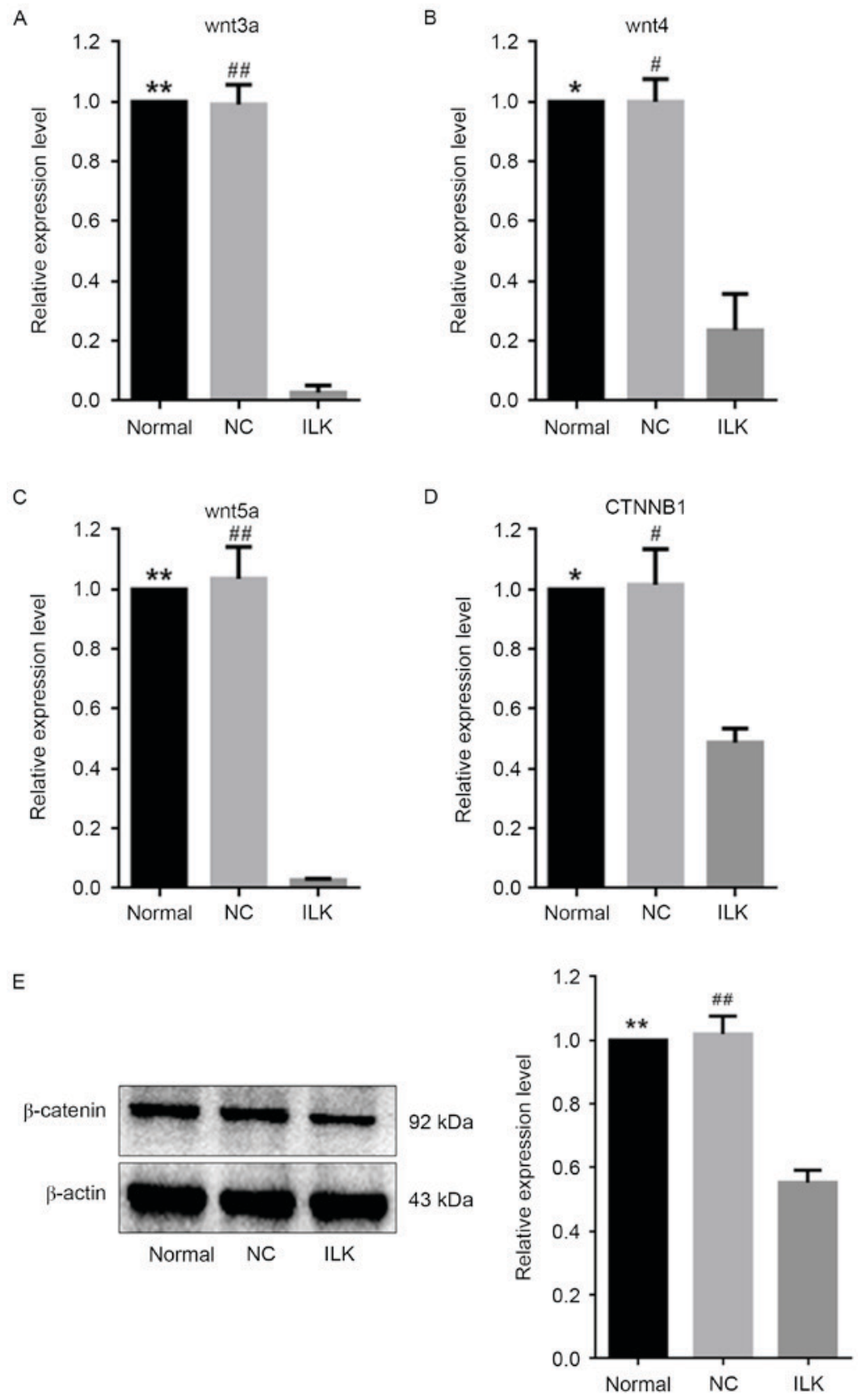

Figure 5. ILK silencing causes reduced activity of the wnt signaling pathway. mRNA expression levels of (A) wnt3a, (B) $w n t 4$ and (C) $w n t 5 a$ were significantly downregulated by $I L K$ short hairpin RNA lentivirus transfection $(\mathrm{n}=3)$. $\beta$-catenin was studied at both the (D) RNA and (E) protein expression levels. Data are expressed as the mean \pm standard error. ${ }^{*} \mathrm{P}<0.01,{ }^{* *} \mathrm{P}<0.001$ vs. normal cells; ${ }^{*} \mathrm{P}<0.01,{ }^{\# \#} \mathrm{P}<0.001$, vs. NC. CTNBB1, $\beta$-catenin; ILK, integrin-linked kinase; NC, negative control.

significant enrichment for genes in cancer-associated pathways. This finding was consistent with the changes in cell phenotypes after $I L K$ silencing $(10,11)$. Overrepresentation of target genes involved in focal adhesion $\left(\mathrm{FDR}=1 \times 10^{-7}\right)$ was consistent with previous observations by Wang and Basson (37), who demonstrated that $I L K$ silencing causes reduced phosphorylation of FAK and Akt in cancer cells. The phosphorylation of FAK and Akt is necessary for pressure-stimulated cancer cell adhesion. In the present study, it was observed that ILK silencing down-regulated the activity of the FAK/Akt signaling pathway. By regulating the expression of multiple miRNAs that target genes in the focal adhesion pathway, ILK may serve a vital role in cell adhesion, an important biological process leading to cancer metastasis. Cell adhesion was impaired when ILK was silenced in OC cells. Further experiments are needed to validate this finding obtained by our pathway analysis.

A miRNA-mediated functional association between ILK and the wnt signaling pathway was also detected. Inhibition of the wnt signaling pathway leads to apoptosis in OC cells (15-18). In the present study, $I L K$ silencing substantially increased the levels of four miRNAs (miR-15a-5p, miR-29c-3p, miR-30a-5p and miR-200a-3p) that regulate genes in the wnt signaling pathway and caused significant downregulation of target genes, including wnt $3 a$, wnt 4 , wnt5a and CTNNB1 (25-28). Decreased expression of $\beta$-catenin suggests reduced activity of the wnt signaling pathway (38). Oloumi et al (39) have 
demonstrated that the pharmacological inhibition of ILK results in the suppression of the nuclear stabilization of $\beta$-catenin in wnt3a-expressing cells. This result was consistent with the finding that $I L K$ silencing inhibited the activity of the wnt signaling pathway via miRNA-mediated target gene regulation.

In conclusion, the present study investigated the roles of ILK in OC based on global miRNA expression analysis. Specific $I L K$ silencing induced significant alterations in the expression of many miRNAs, suggesting multi-faceted roles of ILK in OC. Furthermore, ILK-mediated modulation of the wnt signaling pathway via multiple miRNAs was identified in the present study. This finding implies indirect functional interactions between ILK and the wnt signaling pathway, both of which have roles in OC progression.

\section{Acknowledgements}

The present study was supported by the National Natural Science Foundation of China (grant nos. 81401502 and 31301095) and the Research Foundation of the First Affiliated Hospital of Harbin Medical University (grant nos. 2015 Y006 and 2015B014).

\section{References}

1. Jemal A, Siegel R, Ward E, Hao Y, Xu J and Thun MJ: Cancer statistics, 2009. CA Cancer J Clin 59: 225-249, 2009.

2. Marchetti C, Pisano C, Facchini G, Bruni GS, Magazzino FP, Losito S and Pignata S: First-line treatment of advanced ovarian cancer: Current research and perspectives. Expert Rev Anticancer Ther 10: 47-60, 2010.

3. Cohen JG, White M, Cruz A and Farias-Eisner R: In 2014, can we do better than CA125 in the early detection of ovarian cancer? World J Biol Chem 5: 286-300, 2014.

4. Sopik V, Iqbal J, Rosen B and Narod SA: Why have ovarian cancer mortality rates declined? Part I. Incidence. Gynecol Oncol 138: 741-749, 2015.

5. Sopik V, Iqbal J, Rosen B and Narod SA: Why have ovarian cancer mortality rates declined? Part II. Case-fatality. Gynecol Oncol 138: 750-756, 2015.

6. Ahmed N, Oliva K, Rice GE and Quinn MA: Cell-free 59 kDa immunoreactive integrin-linked kinase: A novel marker for ovarian carcinoma. Clin Cancer Res 10: 2415-2420, 2004.

7. Bagnato $\mathrm{A}$ and Rosanò L: Epithelial-mesenchymal transition in ovarian cancer progression: A crucial role for the endothelin axis. Cells Tissues Organs 185: 85-94, 2007.

8. Ahmed N, Riley C, Oliva K, Stutt E, Rice GE and Quinn MA: Integrin-linked kinase expression increases with ovarian tumour grade and is sustained by peritoneal tumour fluid. J Pathol 201: 229-237, 2003

9. Lössner D, Abou-Ajram C, Benge A, Aumercier M, Schmitt M and Reuning U: Integrin alphavbeta 3 upregulates integrin-linked kinase expression in human ovarian cancer cells via enhancement of ILK gene transcription. J Cell Physiol 220: 367-375, 2009.

10. Liu Q, Xiao L, Yuan D, Shi X and Li P: Silencing of the integrin-linked kinase gene induces the apoptosis in ovarian carcinoma. J Recept Signal Transduct Res 32: 120-127, 2012.

11. Li Q, Li C, Zhang YY, Chen W, Lv JL, Sun J and You QS: Silencing of integrin-linked kinase suppresses in vivo tumorigenesis of human ovarian carcinoma cells. Mol Med Rep 7: 1050-1054, 2013

12. Oloumi A, Maidan M, Lock FE, Tearle H, McKinney S, Muller WJ, Aparicio SA and Dedhar S: Cooperative signaling between Wntl and integrin-linked kinase induces accelerated breast tumor development. Breast Cancer Res 12: R38, 2010.

13. Oneyama C, Morii E, Okuzaki D, Takahashi Y, Ikeda J, Wakabayashi N, Akamatsu H, Tsujimoto M, Nishida T, Aozasa K and Okada M: MicroRNA-mediated upregulation of integrin-linked kinase promotes Src-induced tumor progression. Oncogene 31: 1623-1635, 2012.
14. Ghahhari NM and Babashah S: Interplay between microRNAs and WNT/ $\beta$-catenin signalling pathway regulates epithelial-mesenchymal transition in cancer. Eur J Cancer 51: 1638-1649, 2015.

15. Wang H, Fan L, Xia X, Rao Y, Ma Q, Yang J, Lu Y, Wang C, Ma D and Huang X: Silencing Wnt2B by siRNA interference inhibits metastasis and enhances chemotherapy sensitivity in ovarian cancer. Int J Gynecol Cancer 22: 755-761, 2012.

16. Sanchez AM, Giorgione V, Viganò P, Papaleo E, Candiani M, Mangili G and Panina-Bordignon P: Treatment with anticancer agents induces dysregulation of specific Wnt signaling pathways in human ovarian luteinized granulosa cells in vitro. Toxicol Sci 136: 183-192, 2013.

17. Liu H, Yan ZQ, Li B, Yin SY, Sun Q, Kou JJ, Ye D, Ferns K, Liu HY and Liu SL: Reduced expression of SOX7 in ovarian cancer: A novel tumor suppressor through the $\mathrm{Wnt} / \beta$-catenin signaling pathway. J Ovarian Res 7: 87, 2014.

18. Meng J, Zhang D, Pan N, Sun N, Wang Q, Fan J, Zhou P Zhu W and Jiang L: Identification of miR-194-5p as a potential biomarker for postmenopausal osteoporosis. Peer J 3: e971, 2015.

19. Livak KJ and Schmittgen TD: Analysis of relative gene expression data using real-time quantitative PCR and the 2(-Delta Delta C(T)) method. Methods 25: 402-408, 2001

20. Huang da W, Sherman BT and Lempicki RA: Systematic and integrative analysis of large gene lists using DAVID bioinformatics resources. Nat Protoc 4: 44-57, 2009.

21. Hsu SD, Tseng YT, Shrestha S, Lin YL, Khaleel A, Chou CH, Chu CF, Huang HY, Lin CM, Ho SY, et al: miRTarBase update 2014: An information resource for experimentally validated miRNA-target interactions. Nucleic Acids Res 42 (Database Issue): D78-D85, 2014.

22. Thamilselvan V, Craig DH and Basson MD: FAK association with multiple signal proteins mediates pressure-induced colon cancer cell adhesion via a Src-dependent PI3K/Akt pathway. FASEB J 21: 1730-1741, 2007.

23. Rosanò L, Cianfrocca R, Tocci P, Spinella F, Di Castro V, Caprara V, Semprucci E, Ferrandina G, Natali PG and Bagnato A: Endothelin A receptor/ $\beta$-arrestin signaling to the Wnt pathway renders ovarian cancer cells resistant to chemotherapy. Cancer Res 74: 7453-7464, 2014.

24. Mostowska A, Pawlik P, Sajdak S, Markowska J, Pawałowska M, Lianeri M and Jagodzinski PP: An analysis of polymorphisms within the Wnt signaling pathway in relation to ovarian cancer risk in a Polish population. Mol Diagn Ther 18: 85-91, 2014.

25. Bonci D, Coppola V, Musumeci M, Addario A, Giuffrida R, Memeo L, D'Urso L, Pagliuca A, Biffoni M, Labbaye C, et al: The miR-15a-miR-16-1 cluster controls prostate cancer by targeting multiple oncogenic activities. Nat Med 14: 1271-1277, 2008.

26. Hawkins SM, Creighton CJ, Han DY, Zariff A, Anderson ML, Gunaratne PH and Matzuk MM: Functional microRNA involved in endometriosis. Mol Endocrinol 25: 821-832, 2011.

27. Selbach M, Schwanhäusser B, Thierfelder N, Fang Z, Khanin R and Rajewsky N: Widespread changes in protein synthesis induced by microRNAs. Nature 455: 58-63, 2008.

28. Xia H, Ng SS, Jiang S, Cheung WK, Sze J, Bian XW, Kung HF and Lin MC: miR-200a-mediated downregulation of ZEB2 and CTNNB1 differentially inhibits nasopharyngeal carcinoma cell growth, migration and invasion. Biochem Biophys Res Commun 391: 535-541, 2010.

29. Cortez V, Nair BC, Chakravarty D and Vadlamudi RK: Integrin-linked kinase 1: Role in hormonal cancer progression. Front Biosci (Schol Ed) 3: 788-796, 2011.

30. Luo P, Fei J, Zhou J and Zhang W: microRNA-126 suppresses PAK4 expression in ovarian cancer SKOV3 cells. Oncol Lett 9: 2225-2229, 2015.

31. Guo T, Yu W, Lv S, Zhang C and Tian Y: miR-302a inhibits the tumorigenicity of ovarian cancer cells by suppression of SDC1. Int J Clin Exp Pathol 8: 4869-4880, 2015.

32. Fan Y, Fan J, Huang L, Ye M, Huang Z, Wang Y, Li Q and Huang J: Increased expression of microRNA-196a predicts poor prognosis in human ovarian carcinoma. Int J Clin Exp Pathol 8: 4132-4137, 2015.

33. Muralidhar GG and Barbolina MV: The miR-200 Family: Versatile players in epithelial ovarian cancer. Int J Mol Sci 16: 16833-16847, 2015.

34. Liu R, Liu F, Li L, Sun M and Chen K: miR-498 regulated FOXO3 expression and inhibited the proliferation of human ovarian cancer cells. Biomed Pharmacother 72: 52-57, 2015. 
35. Wen Z, Zhao S, Liu S, Liu Y, Li X and Li S: MicroRNA-148a inhibits migration and invasion of ovarian cancer cells via targeting sphingosine-1-phosphate receptor 1. Mol Med Rep 12: 3775-3780, 2015 .

36. Choi YP, Kim BG, Gao MQ, Kang S and Cho NH: Targeting ILK and $\beta 4$ integrin abrogates the invasive potential of ovarian cancer. Biochem Biophys Res Commun 427: 642-648, 2012.

37. Wang S and Basson MD: Integrin-linked kinase: A multi-functional regulator modulating extracellular pressure-stimulated cancer cell adhesion through focal adhesion kinase and AKT. Cell Oncol 31: 273-289, 2009.
38. Yoshioka S, King ML, Ran S, Okuda H, MacLean JA II, McAsey ME, Sugino N, Brard L, Watabe K and Hayashi K: WNT7A regulates tumor growth and progression in ovarian cancer through the WNT/ $\beta$-catenin pathway. Mol Cancer Res 10: 469-482, 2012

39. Oloumi A, Syam S and Dedhar S: Modulation of Wnt3a-mediated nuclear beta-catenin accumulation and activation by integrin-linked kinase in mammalian cells. Oncogene 25: 7747-7757, 2006. 